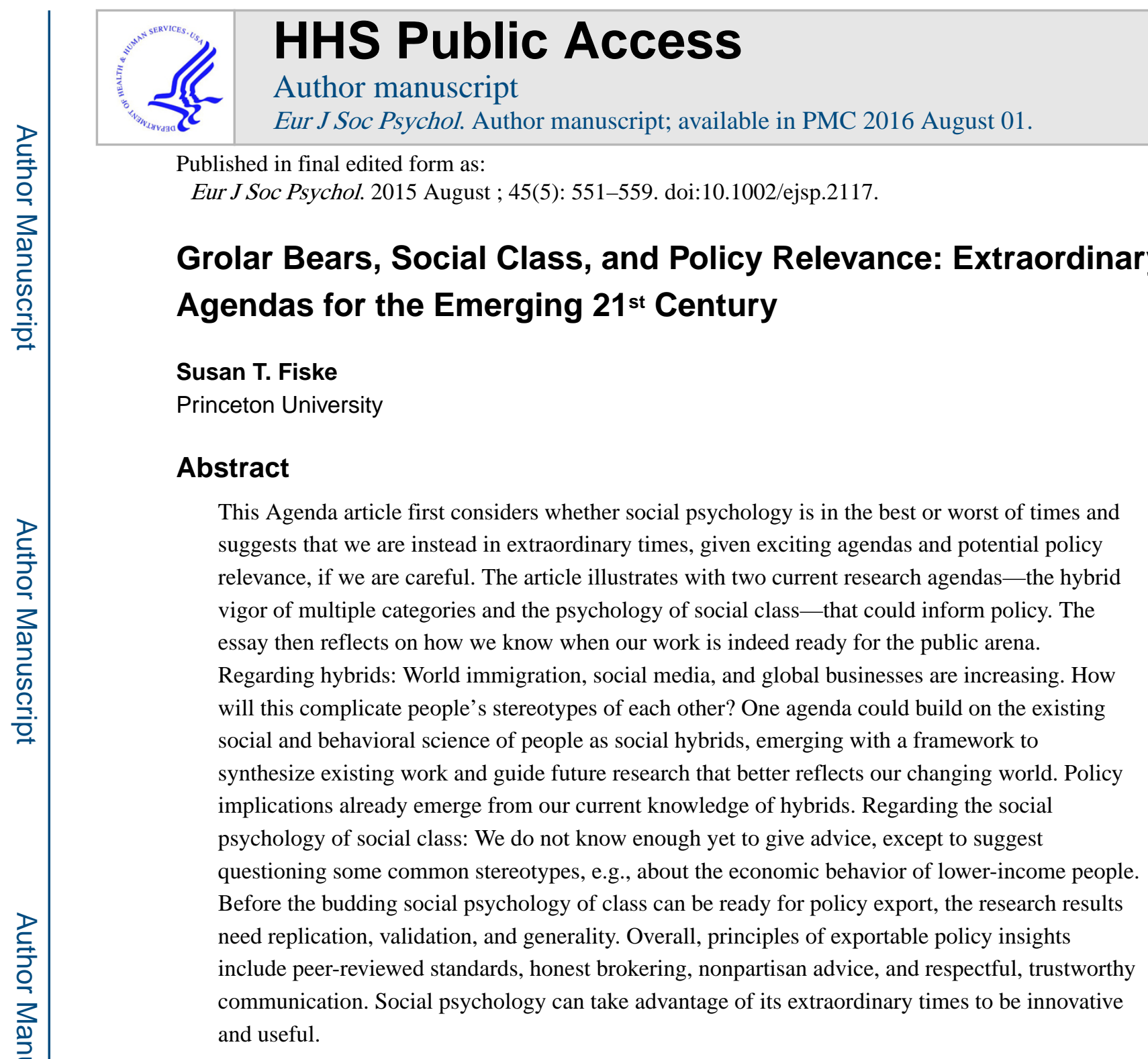

These days, we are more and more called to justify our science-at the same time that we have never before been so popular. Are we in the best or worst of times? The author is inclined to believe we are in extraordinary times with extraordinary opportunities, illustrated here by two research agendas and their policy potentials.

\title{
Best of Times?
}

The average media consumer knows more social psychology than ever, as we appear in newspapers, radio, blogs, tweets, advertisements, and bestsellers. To illustrate: The New York Times (NYT) regularly publishes op-eds by our colleagues, and reports of our findings are often the most emailed science articles. A NYTblog, the Opinionator, yields 90 hits for social psychology (http://opinionator.blogs.nytimes.com/ searched January 25, 2015). The same search of the NYT Science section yielded 17,567 hits, about one social psychology piece a week in recent months. Collectively, we're publishing scores of popular books (from the same search on Amazon.com), to name a random few: Blindspot: Hidden Biases of Good People (Banaji \& Greenwald, 2013), Sex, Murder, and the Meaning of Life: A Psychologist Investigates How Evolution, Cognition, and Complexity are Revolutionizing 
Our View of Human Nature (Kenrick, 2011), Social: Why Our Brains Are Wired to Connect (Lieberman, 2013), Clash: How to Thrive in a Multicultural World (Markus \& Connor, 2013), Whistling Vivaldi: How Stereotypes Affect Us and What We Can Do (Steele, 2010), Redirect: Changing the Stories We Live By (Wilson, 2011). Precedents for the current burst of popular treatments include The Tipping Point: How Little Things Can Make a Big Difference (Gladwell, 2000) and Stumbling on Happiness (Gilbert, 2006). It is hard to remember that social psychologists did not always used to write trade books. But the public finds us appealing, and these are one way to get our work out there.

Indeed, some governments also see the usefulness of our advice, as in the UK Behavioral Insights Team (the "nudge unit"), the parallel U.S. Social and Behavioral Sciences Team, and the Danish Nudging Network, among others. Our journals have long recognized the potential of social psychology for policy: from the earlier Journal of Social Issues and Basic and Applied Social Psychology, for example, more specifically policy-oriented journals have launched: Policy Insights from Behavioral and Brain Sciences, Behavioral Science and Policy, Analyses of Social Issues and Public Policy. And these are just American examples.

Not only do the public and policymakers take an interest, but informal observation suggests that both graduate and undergraduates are flocking to our classes and degree programs. Social psychology potentially appeals as a science, as entertainment, and as policymaking.

\section{Worst of Times?}

While all this might seem an unalloyed good, attention brings with it a critical eye. My most recent hate mail, as I write, came from someone wanting to know why we think we can play with human beings. The public is not always happy to participate in our increasingly public research, as Facebook discovered when it manipulated users' newsfeeds by removing $90 \%$ of their friends' cheerful posts or grim posts for a week, to study emotional contagion (Kramer, Guillory, \& Hancock, 2014). (The facts -that Facebook algorithms already manipulated newsfeeds all the item and that users agree to research as a condition of joining —did not mollify many angry users. Many of them blamed social psychology at least as much as Facebook.

Because our science investigates everyday social interactions, the public and policy makers feel entitled to have strong opinions about its value, even when they are not participants. As social psychology blogs and webpages attest, lay people weigh in, sometimes regardless of the evidence. Like some of the commenters, generations of undergraduates have had to learn the difference between anecdotes and data. Nevertheless, the criticisms are real.

We are not innocent in all this. Social psychology's appeal as science can conflict with its role as entertainment, and both can conflict with the political agendas of policymaking. The popularity of our findings can tempt us to go public with a one-shot study, offered as a factoid in the media: Did you know that people do what you least expect? Later, this article will take up when scientists should go public, especially in consequential policy contexts, but for now the point is that ephemeral entertainment value can pressure against scientific caution to make premature claims. Piecemeal publication moreover does not cumulate to 
create theoretical insight (Ellemers, 2013). Over time, this premature enthusiasm can undermine our credibility.

More financially impactful judgments come from our government funders, who want justification for the (shrinking) research support they still provide. Social psychology seems like common sense (which is not necessarily common or sensible), so why waste public funds on it? Politically motivated attacks on injudiciously titled grant proposals further make our science look frivolous and do not help our reputation.

Even more damaging than cute studies are fake ones. Not to rehash the scandals (see Finkel, Eastwick, \& Reis, 2015, for a balanced perspective), but the issues run from difficulties in replication to borderline methods to falsified data. These each have a variety of causes, but striving for rapid impact is surely one of them. Other fields are not immune to the same pressures and perhaps more so-given the potential for patents and profits that some of them offer. Social psychology researchers can be grateful that at least money is rarely on offer to tempt us to misbehave.

But these cross-pressures are not new: We have been accused of being fast and loose before (Greenwald, 1976). And we have been accused of being too cute before (Ring, 1967). Indeed, some of us came of age professionally just after an earlier crisis in social psychology (Deutsch, 1979; Lewin, 1977; Nelson \& Kennenberg, 1976; Sherif, 1977); suitably chastised to be serious, we were grateful that the field even continued. Last time, the crisis essentially emphasized theoretical superficiality and general uselessness, although replicability was also at issue (Greenwald, 1976). Since then, the proliferation of theory (e.g., Van Lange, Kruglanski, \& Higgins, 2012), methodological rigor (e.g., Reis \& Judd, 2014), and demonstrable applicability (e.g., Taylor, 1990) quelled that crisis.

Apparently there had been a crisis already in 1927 (Lewin, 1977). Debate and controversy are not intrinsically damaging; indeed they are often improving. Perhaps periodic crises refresh the field though urgent self-examination.

\section{Extraordinary Times!}

Call me Pollyanna, but I believe these are exciting times for our field. A previous agenda article argued for the roles of evolution, brain, mind, and culture (Fiske, 2000), trends that continue to be stimulating. Here, to illustrate some other exciting and possibly coming policy-relevant trends, this Agenda article presents two emerging areas of research-the hybrid vigor of multiple categories and the psychology of social class. These are linked not only in being exciting cutting-edge areas that appeal to this author. Hybrids and social class interplay with each other, and each could inform policy. The essay finally reflects on how we know when our work is indeed ready for the public arena in these extraordinary times.

\section{Human Hybrids: Our New Poly-Cultural Worlds}

Global warming is famously endangering polar bears and, less famously, expanding the habitat of grizzly bears who move north and sometimes breed with their cousins, producing 
grolar bears or pizzly bears (Velasquez-Manoffaug, 2014). These still-rare, but not sterile, cross-breeds may display hybrid vigor unavailable to their forebears.

Hybrid vigor is a $21^{\text {st }}$ century fact for humans as well, but in social forms, at least as much as on genetic levels. Indeed, maybe "mash-up" is a better term, linking better to cultural creations. Globalizing business, easing travel, increasing immigration, gaining poly-cultural competence, using social media, and growing intermarriage - all create a social psychological framework for new blends in how we think about ourselves and each other. Widening inequality also forces one to consider blends of each category mixing with social class. As an example of the hybrid (mash-up) trends, racial categories are no longer simple, as many popular entertainments show (among them: Smart People, a play by Lydia Diamond, inspired in part by some recent social neuroscience-Harris \& Fiske, 2006; Phelps et al., 2000). Millennials are more ethnically diverse than previous generations (Pew, 2014) and more nuanced about the categories they own and perceive in others. Mash-ups are on the rise.

We already know that single demographic categories have immediate consequences. As three decades of studies show, people instantly respond to each other's apparent race, gender, age, and class (Fazio \& Olson, 2003; Greenwald \& Banaji, 1995; Macrae \& Bodenhausen, 2000). We already know that these instant categorical responses register even at the level of the brain, activating networks of associations, emotions, and impulses to react. We already know that prejudices in favor of "us" result in prejudices against "them" (Tajfel \& Turner, 1979) from the first milliseconds of an encounter (Fiske \& Taylor, 2013, Ch. 3, 11).

What we do not already know is how these rapid responses operate in the context of hybrids, people who are cosmopolitan, ambiguous, complex, shifting blends of multiple categories. In short, we don't know much about what will increasingly define the $21^{\text {st }}$ century's demographic realities. Distinguished commentators have interrogated these phenomena (e.g., Appiah, 2010), expressing their import.

To be sure, social scientists generally, and social psychologists specifically, have examined poly-culturalism, intersectionality, super-diversity, and multiple identities (e.g., Crul, Schneider, \& Lelie, 2013; Kang \& Bodenhausen, 2014; Morris, Liu, \& Chiu, 2014; Vertovec, 2007). Social psychologists have studied what makes one category active and another dormant, how minds shift from one category to another. Both momentary goals (e.g., Macrae, Bodenhausen, \& Milne, 1998) and situational fit (Turner et al., 1987) can emphasize one category and shelve another.

What we have not fully studied is people's ability to hold multiple categories simultaneously for themselves and others, without reducing the other to a subtype. To illustrate the subtyping exception, our own research has examined the interplay of race and class, showing that many Americans more rapidly associate high-status jobs with Whites and low-status jobs with Blacks (Dupree, Obioha, \& Fiske, 2014). Beyond this Black-is-poor default, many Americans also possess subtyped, separate images of poor Blacks and Black professionals (Fiske, Cuddy, \& Glick, 2007; see an earlier analysis of race-by-class subtypes, Stangor, 
Lynch, Duan, \& Glas, 1992). And Black Americans themselves report multiple subtypes of African Americans (Fiske, Bergsieker, Russell, \& Williams, 2009). In another domain, overall images of gay men may revolve around a default that they are artistic, but this is only one of a dozen familiar subtypes differentiated by subtyped gay styles and professions (Clausell \& Fiske, 2005; see similar analyses of older-age subtypes by Brewer, Dull, \& Lui, 1981). Subtypes cross two categories and still produce one (more specialized) category.

A related, also well-trodden approach examines the interactions of two or more categories. For example, prior insights have illuminated crossed categories (e.g., two people identified by both ethnicity and religion), with a variety of salutary results on intergroup tensions, especially given: crossed categories that are contradictory (e.g., an obese model; Vasiljevic \& Crisp, 2013), that include one overlapping ingroup (e.g., Crisp, Walsh, \& Hewstone, 2006), that emphasize both groups sharing a overarching, common ingroup identity (Gaertner \& Dovidio, 2000), or that include more than one shared ingroup, wherein their relative importance matters (Urada, Sternstrom \& Miller, 2007; see also Ashmore, Deaux, \& McLaughlin-Volpe, 2004). In theory, two categories could result in intersectional invisibility, for example when an ethnic minority woman does not seem prototypic of either her gender or her ethnicity (Purdie-Vaughns \& Eibach, 2008).

Going beyond subtypes and dual (dueling?) categories, something new, less divisive, and more nuanced happens when multiple categories combine. This represents a demographic reality (e.g., race and class interact, Massey \& Brodmann, 2014), but it also mentally mixes and dilutes common images, resulting in mashed-up hybrids.

To be clear, combining demographic categories into mash-ups creates a more distinctive individual image, but it does not fully personalize or individuate the other. Individuation goes beyond demographic categories to understand another individual's heart and mind (Fiske \& Neuberg, 1990; see also personalization, Brewer, 1988). Individuation involves perceiving another person as more fully human by considering the person's intentions, beliefs, and preferences (Swencionis \& Fiske, 2014). Individuation swamps the demographic categories with unique personality traits, personal goals, distinct opinions, and so on. Fullblown individuation takes attention, motivation, and time, not always pragmatic in the blooming, buzzing confusion of everyday life.

Instead, the hybrid gap lies somewhere between the most simplistic single-category (and even dual-category) stereotyping and the most nuanced, individuated impression. The question is how a perceiver holds multiple categories in mind at once. An earlier effort along these lines pursued automatic, simultaneous, multiple-constraint satisfaction in a parallel distributed processing system (Kunda \& Thagard, 1996). For the multiple-category combination, this model posits, "A stereotype can influence the activation of subtypes of another stereotype." This comprehensive framework operates within a computational model that complements the more mid-level approach proposed here.

The point is that studying hybrid mash-ups is potentially exciting research that social psychologists are well suited to do. In these exciting times, this topic fits the science, the entertainment, and as the next point will argue, the policy demands. 
The policy agendas resulting from what we already know about hybrids suggest, first, that no policy can be one-size-fits-all. Not all minorities experience stereotype threat; for example, immigrant Black Americans respond differently from native-born Black Americans (Deaux et al., 2007). Not all women want to juggle family and career; women differ in their endorsement of benevolent sexism prescribing traditional roles (e.g., Gaunt, 2013; Travaglia, Overall, \& Sibley, 2009). Culture determines roles for older people; for example elders are not more revered in the East than the West, but as a function of being industrialized or not (North \& Fiske, 2014). Interventions must take account of variability by culture but also within culture, and acknowledge individuals who inhabit multiple cultures (Morris et al., 2014). Every category has mash-ups and nuances.

Perhaps the best way to diagnose the relevant demographic categories is not to assume but to ask. "Ascertaining which identities matter" is a social identity approach in real-world settings that does not assume that one knows which categories matter for the individual or group without checking (e.g., Haslam, 2014).

For social psychologists, the policy-relevant research agenda entails drawing on work both within and beyond our field. The result will be a framework to integrate what we know and to specify what we do not yet know but should, as well as setting a research agenda for the $21^{\text {st }}$ century hybrids we all are becoming.

\section{Social Psychology of Social Class}

One specific factor that repeatedly creates mash-ups is social class. In contrast to the social psychology of hybrids, we know relatively little about the face-to-face social psychology of social class. An edited volume just a couple of years ago (Fiske \& Markus, 2012) collected a dozen initial contributions to this emerging area: Only five of the chapters were authored by psychological social psychologists (as opposed to sociologists and anthropologists, who have been doing social class far longer). Those topics included class and institutional culture (Stephens, Fryberg, \& Markus, 2012), face-to-face encounters (Kraus, Rheinschmidt, \& Piff, 2012), decision-making constraints (Hall, 2012), racial fluidity (Sanchez \& Garcia, 2012), and trust (Fiske, Moya, Russell, \& Bearns, 2012)—a range, but still fewer than half-a-dozen labs.

Just a couple years later, Miguel Moya and I put out a call for an EASP/SPSSI small group meeting at Princeton, focused on social class divides: We had 25 presentations, plus more who could not be accommodated within the small-group format. The topics' range already developed the work begun earlier on class issues in a variety of contexts: the institutional culture of education (Markus, 2014; Stephens, 2014; see also Butera, Autin, \& Batruch, 2014), face-to-face encounters (Kraus, 2014), decision-making constraints (Shafir, 2014; see also Hall, Galvez, \& Sederbaum, 2014), and trust (Bearns-Tablante, Fiske, \& Moya, 2014; Moya, Valor-Segura, \& Navarro, 2014).

Among the new directions are class identity related to individual mobility (Covarrubias \& Fryberg, 2014; Jury, 2014; Kuppens, 2014; Spears \& Suhlmann, 2014) and reactions to group disadvantage (Loughnan, 2014; Owuamalam, Rubin, \& Issmer, 2014). Income 
inequality and the recession specifically prompt causal analysis (Bukowski, de Lemus, Rodriguez-Bailon, \& Willis, 2014; Fritsche, 2014) and system justification (Durante, Fiske, Gelfand, et al., 2014; Kay, 2014; Rodriguez-Bailon, Willis, Lopez-Rodriguez, Dovidio, \& Horwitz, 2014). Class attitudes play a critical role (Horwitz \& Dovidio, 2014; Jetten, 2014).

At the level of face-to-face encounters came new work on cross-status impression management (Dupree \& Fiske, 2014; Swencionis \& Fiske, 2014) and interpersonal control (Andrighetto, 2014; Becker, 2014; Bukowski, de Lemus, Rodriguez-Bailon, \& Willis, 2014; Greenaway, 2014; Stamkou, 2014).

Clearly, the effects of societal rank on intergroup and interpersonal interaction is inspiring rich research agendas. This work is notable for operating at multiple levels of analysis, from culture to individuals, as indicated. This work also operationalizes social class in a stunning variety of ways: subjective class, comparative class, education, family income, personal income, and job status, to name a few. The methods range from cross-national surveys of income inequality to split-second individual responses. As implied, the theoretical approaches also draw on a wide range of social psychology, and the current work leaves room for even more. The social class research is work in progress, with only a few exceptions ready for export, which brings us to the final topic of this essay.

\section{Policy Insights from Social Psychology}

To be sure, although it is the best of times, with us in much demand and an exciting future, it is also the worst of times because of some aforementioned crises, so we must be careful. Much has been said elsewhere about being scientifically careful. Here the article addresses how to be careful about policy.

Many social psychologists want to be useful to society, so we work on social issues and hope to offer insights. Collections are beginning to represent our offerings to the policy world (e.g., Shafir, 2013). Much social psychology is ready for export. For example, the field of education can learn much from research on stereotype threat, implicit bias, ambivalent sexism, bullying, and ostracism. Workplaces and organizations can profit from understanding ingroup favoritism, identity development, cultural psychology, implicit prejudice, and diversity science more generally. The justice system can consider racial biases, social identity threat, authority attitudes, social influence, and deception detection. Public welfare can weigh decision-making constraints, dehumanization, and inequality preferences. Negotiators can balance attributional asymmetries, power relations, and biased perspectives. Protection against terrorism can be strengthened by understanding intergroup motivations and social identity. Sustainability can integrate social influence and decisionmaking heuristics. Health and wellbeing can benefit from valuing education, happiness, inclusion, self-affirmation, commitment, constructive comparisons, and reciprocity (see Policy Insights from the Behavioral and Brain Sciences, 2014, for these examples).

In conveying social psychology, we must be honest brokers for quality science, which is peer-reviewed results, not merely expert opinion, however plausible. We must convey the accumulated scientific consensus, not just today's cutting-edge finding that may not 
replicate or survive vetting. We establish scientific consensus by a variety of means (Fiske $\&$ Borgida, 2011): meta-analyses, narrative literature reviews, professional society consensus reports, surveys of experts, or adversarial collaboration.

To retain our scientific credibility, we must be honest brokers who are both competent and trustworthy. Our status as scientists wins respect, but not necessarily trust (Fiske \& Dupree, 2014). We must therefore demonstrate worthy intentions, being nonpartisan and open about the limits of what we know. The science of science communication is more than public relations; it is our public obligation. Indeed the U.S. National Academy of Sciences has sponsored a series of colloquia on this topic (Fischhoff \& Scheufele, 2013, 2014).

\section{Conclusions}

Perhaps this is social psychology's best of times-we are in great public demand. Perhaps it is our worst of times - we must defend our standards, our contributions, and our agendas. Or perhaps this is social psychology's extraordinary times. We are more than up to the challenge, as scanning research topics from any of our journals or conferences will show. The excitement of cutting-edge research, being in demand by the public, and shaping policy all can motivate scientists. We can also learn from the lessons of our field's crises. We can be at once careful and joyful in these extraordinary times.

\section{References}

Andrighetto, L. (Still) "Modern Times": Objectification at work. Paper presented at EASP/SPSSI Small Group Meeting, The Great Recession and Social Class Divides; September 4-6, 2014; Princeton University; 2014.

Appiah, KA. Cosmopolitanism: Ethics in a world of strangers. New York: Norton; 2010.

Ashmore RD, Deaux K, McLaughlin-Volpe T. An organizing framework for collective identity: Articulation and significance of multidimensionality. Psychological Bulletin. 2004; 130(1):80-114. [PubMed: 14717651]

Banaji, MB.; Greenwald, AG. Blindspot: Hidden Biases of Good People. New York: Random House; 2013.

Becker, J. Vicarious protest: How the middle class excludes the working class from protest against social injustice. Paper presented at EASP/SPSSI Small Group Meeting, The Great Recession and Social Class Divides; September 4-6, 2014; Princeton University; 2014.

Brewer, MB. A dual process model of impression formation. In: Srull, TK.; Wyer, RS., Jr, editors. Advances in social cognition, Vol. 1. A dual process model of impression formation. Hillsdale, NJ: Lawrence Erlbaum Associates; 1988. p. 1-36.

Brewer MB, Dull V, Lui L. Perceptions of the elderly: Stereotypes as prototypes. Journal of Personality and Social Psychology. 1981; 41(4):656-670.

Bukowski, M.; de Lemus, S.; Rodriguez-Bailon, R.; Willis, GB. Who's to blame? Causal attributions of the economic recession and personal control. Paper presented at EASP/SPSSI Small Group Meeting, The Great Recession and Social Class Divides; September 4-6, 2014; Princeton University; 2014.

Butera, F.; Autin, F.; Batruch, A. The irony of merit-based selection: Normative assessment and school tracking promote social class inequalities in educational attainment. Paper presented at EASP/SPSSI Small Group Meeting, The Great Recession and Social Class Divides; September 4-6, 2014; Princeton University; 2014.

Clausell E, Fiske ST. When do the parts add up to the whole? Ambivalent stereotype content for gay male subgroups. Social Cognition. 2005; 23:157-176. 
Covarrubias, R.; Fryberg, SA. Movin' on up (to college): First generation college students' experiences with family achievement guilt. Paper presented at EASP/SPSSI Small Group Meeting, The Great Recession and Social Class Divides; September 4-6, 2014; Princeton University; 2014.

Crisp, RJ.; Hewstone, M. Multiple social categorization. In: Zanna, MP., editor. Advances in experimental social psychology. Vol. 39. 2007. p. 163-254.

Crisp RJ, Walsh J, Hewstone M. Crossed categorization in common ingroup contexts. Personality and Social Psychology Bulletin. 2006; 32(9):1204-1218. [PubMed: 16902240]

Crul MRJ, Schneider J, Lelie F. Super-diversity: A new perspective on integration. 2013 dare.ubvu.vu.nl.

Deaux K, Bikmen N, Gilkes A, Ventuneac A, Joseph Y, Payne YA, Steele CM. Becoming American: Stereotype threat effects in afro-caribbean immigrant groups. Social Psychology Quarterly. 2007; 70(4):384-404.

Deutsch M. Some comments on the current status of American social psychology. Japanese Journal of Experimental Social Psychology. 1979; 18(2):167-171. http://dx.doi.org/10.2130/jjesp.18.167.

Diamond, LR. Smart People. Huntington Theater: Boston University; 2014. Performed May 23-July 6, 2014

Dupree, C.; Fiske, ST. Does race imitate status?. Paper presented at EASP/SPSSI Small Group Meeting, The Great Recession and Social Class Divides; September 4-6, 2014; Princeton University; 2014.

Dupree C, Obioha O, Fiske ST. Automatic race-by-class intersectionality. 2014 Unpublished manuscript.

Durante, F.; Fiske, ST.; Gelfand, M., et al. Income inequality, conflict, and ambivalence in stereotype content. Paper presented at EASP/SPSSI Small Group Meeting, The Great Recession and Social Class Divides; September 4-6, 2014; Princeton University; 2014.

Ellemers N. Connecting the dots: Mobilizing theory to reveal the big picture in social psychology (and why we should do this). European Journal of Social Psychology. 2013; 43(1):1-8.

Fazio RH, Olson MA. Implicit measures in social cognition research: Their meaning and uses. Annual Review of Psychology. 2003; 54:297-327.

Fischhoff B, Scheufele DA. Introduction: The science of science communication. PNAS. 2013; 110(Supplement 3):14031-14032. [PubMed: 23942127]

Fiske ST. Stereotyping, prejudice, and discrimination at the seam between the centuries: Evolution, culture, mind, and brain. European Journal of Social Psychology. 2000; 30:299-322.

Fiske ST, Bergsieker H, Russell AM, Williams L. Images of Black Americans: Then, "them” and now, “Obama!”. DuBois Review: Social Science Research on Race. 2009; 6:83-101.

Fiske ST, Borgida E. Best practices: How to evaluate psychological science for use by organizations. Research in Organizational Behavior. 2011; 31:253-275. [PubMed: 24478533]

Fiske ST, Cuddy AJC, Glick P. Universal dimensions of social perception: Warmth and competence. Trends in Cognitive Science. 2007; 11:77-83.

Fiske ST, Dupree C. Gaining trust as well as respect in communicating to motivated audiences about science topics. PNAS: Proceedings of the National Academy of Sciences of the United States of America. (in press).

Fiske, ST.; Markus, HR., editors. Facing social class: How societal rank influences interaction. New York: Russell Sage Foundation; 2012.

Fiske, ST.; Moya, M.; Russell, AM.; Bearns, C. The secret handshake: Trust in cross-class encounters. In: Fiske, ST.; Markus, HR., editors. Facing social class: How societal rank influences interaction. New York: Russell Sage Foundation; 2012. p. 234-252.(2012)

Fiske, ST.; Neuberg, SL. A continuum model of impression formation, from category-based to individuating processes: Influence of information and motivation on attention and interpretation. In: Zanna, MP., editor. Advances in experimental social psychology. Vol. 23. New York: Academic Press; 1990. p. 1-74.

Fiske, ST.; Taylor, SE. Social cognition: From brains to culture. 2nd. London: Sage; 2013. 
Fritsche, I. The deprivation and collective restoration of control under conditions of economic crisis and social inequality. Paper presented at EASP/SPSSI Small Group Meeting, The Great Recession and Social Class Divides; September 4-6, 2014; Princeton University; 2014.

Gaertner, SL.; Dovidio, JF. Reducing intergroup bias: The common ingroup identity model. New York: Psychology Press; 2000.

Gaunt R. Ambivalent sexism and perceptions of men and women who violate gendered family roles. Community, Work \& Family. 2013; 16(4):401-416.

Gilbert, D. Stumbling on Happiness. New York: Knopf; 2009.

Gladwell, M. The Tipping Point: How Little Things Can Make a Big Difference. New York: Little Brown; 2000.

Greenaway, K. Money and the desire for control. Paper presented at EASP/SPSSI Small Group Meeting, The Great Recession and Social Class Divides; September 4-6, 2014; Princeton University; 2014.

Greenwald AG. An editorial. Journal of Personality and Social Psychology. 1976; 33:1-7.

Greenwald AG, Banaji MR. Implicit social cognition: Attitudes, self-esteem, and stereotypes. Psychological Review. 1995; 102(1):4-27. [PubMed: 7878162]

Hall, CC. Behavioral decision research, social class, and implications for public policy. In: Fiske, ST.; Markus, HR., editors. Facing social class: How societal rank influences interaction. New York: Russell Sage Foundation; 2012. p. 175-194.

Harris LT, Fiske ST. Dehumanizing the lowest of the low: Neuro-imaging responses to extreme outgroups. Psychological Science. 2006; 17:847-853. [PubMed: 17100784]

Haslam SA. Making good theory practical: Five lessons for an applied social identity approach to challenges of organizational, health, and clinical psychology. British Journal of Social Psychology. 2014; 53(1):1-20. [PubMed: 24627990]

Horwitz, S.; Dovidio, JF. Giving an advantage to the advantaged: Attitudes toward the rich influence social judgments. Paper presented at EASP/SPSSI Small Group Meeting, The Great Recession and Social Class Divides; September 4-6, 2014; Princeton University; 2014.

Jetten, J. The wealth paradox: When economic prosperity hardens attitudes towards minorities. Paper presented at EASP/SPSSI Small Group Meeting, The Great Recession and Social Class Divides; September 4-6, 2014; Princeton University; 2014.

Jury, M. Avoiding failure at university: The case of low status high achievers. Paper presented at EASP/SPSSI Small Group Meeting, The Great Recession and Social Class Divides; September 46, 2014; Princeton University; 2014.

Kang SK, Bodenhausen GV. Multiple identities in social perception and interaction: Challenges and opportunities. Annual Review of Psychology. 2014; 66 Advance on-line copy.

Kay, A. The effects of subjective status on political preferences and ideological conflict. Paper presented at EASP/SPSSI Small Group Meeting, The Great Recession and Social Class Divides; September 4-6, 2014; Princeton University; 2014.

Kenrick, DT. Sex, Murder, and the Meaning of Life: A Psychologist Investigates How Evolution, Cognition, and Complexity are Revolutionizing Our View of Human Nature. New York: Basic Books; 2011.

Kramer ADI, Guillory JE, Hancock JT. Experimental evidence of massive-scale emotional contagion through social networks. Proceedings of the National Academy of Sciences. 2014; 111(24):87888790.

Kraus, M. Signaling social class and crossing class boundaries. Paper presented at EASP/SPSSI Small Group Meeting, The Great Recession and Social Class Divides; September 4-6, 2014; Princeton University; 2014.

Kraus, MW.; Rheinschmidt, ML.; Piff, PK. Facing social class: How societal rank influences interaction. Fiske, ST.; Markus, HR., editors. New York: Russell Sage Foundation; 2012. p. 109-130.

Kunda Z, Thagard P. Forming impressions from stereotypes, traits, and behaviors: A parallelconstraint-satisfaction theory. Psychological Review. 1996; 103(2):284-308. 
Kuppens, T. Life at the bottom of the ladder: Education-based identification and well-being, intergroup attitudes, political attitudes, and trust. Paper presented at EASP/SPSSI Small Group Meeting, The Great Recession and Social Class Divides; September 4-6, 2014; Princeton University; 2014.

Lewin MA. Kurt Lewin's view of social psychology: The crisis of 1977 and the crisis of 1927. Personality and Social Psychology Bulletin. 1977; 3(2):159-172.

Lieberman, MD. Social: Why Our Brains Are Wired to Connect. New York: Crown; 2013.

Loughnan, S. Why don't we just redistribute wealth?. Psychological barriers to wealth redistribution amongst the poor; Paper presented at EASP/SPSSI Small Group Meeting, The Great Recession and Social Class Divides; September 4-6, 2014; Princeton University; 2014.

Macrae CN, Bodenhausen GV. Social cognition: Thinking categorically about others. Annual Review of Psychology. 2000; 51:93-120.

Macrae CN, Bodenhausen GV, Milne AB. Saying no to unwanted thoughts: Self-focus and the regulation of mental life. Journal of Personality and Social Psychology. 1998; 74(3):578-589. [PubMed: 9523406]

Markus, HR.; Connor, A. Clash: How to Thrive in a Multicultural World. New York: Hudson Street/ Penguin; 2013.

Markus, HR. Class acts: Socioeconomic cultures. Paper presented at EASP/SPSSI Small Group Meeting, The Great Recession and Social Class Divides; September 4-6, 2014; Princeton University; 2014.

Massey, DS.; Brodmann, S. Spheres of influence: The social ecology of racial and class inequality. New York: Russell Sage Foundation; 2014.

Morris MW, Chiu CY, Liu Z. Polycultural psychology. Annual Review of Psychology. 2014; 66 Advance on-line copy.

Moya, M.; Valor-Segura, I.; Navarro, G. The Great Recession and trust. Paper presented at EASP/ SPSSI Small Group Meeting, The Great Recession and Social Class Divides; September 4-6, 2014; Princeton University; 2014.

Nelson CE, Kennenberg PH. Social psychology in crisis: A study of the references in the Handbook of Social Psychology: (2nd Ed). Personality and Social Psychology Bulletin. 1976; 2(1):14-21.

Owuamalam, C.; Rubin, M.; Issmer, C. Reactions to group disadvantage: A comparison of social identity and system justification predictions. Paper presented at EASP/SPSSI Small Group Meeting, The Great Recession and Social Class Divides; September 4-6, 2014; Princeton University; 2014.

Pew Research. Millennials: Confident. Connected. Open to change. Pew Research Center; 2010 Feb 14. www.pewresearch.org/millennials

Phelps EA, O'Connor KJ, Cunningham WA, Funayama ES, Gatenby JC, Gore JC, Banaji MR. Performance on indirect measures of race evaluation predicts amygdala activation. Journal of Cognitive Neuroscience. 2000; 12:729-738. [PubMed: 11054916]

Purdie-Vaughns V, Eibach RP. Intersectional invisibility: The distinctive advantages and disadvantages of multiple subordinate-group identities. Sex Roles. 2008; 59(5-6):377-391.

Reis, HT.; Judd, CM., editors. Handbook of Research Methods in Social and Personality Psychology. New York: Cambridge; 2014.

Ring K. Experimental social psychology: Some sober questions about some frivolous values. Journal of Experimental Social Psychology. 1967; 3(2):113-123.

Rodriguez-Bailon, R.; Willis, GB.; Lopez-Rodriguez, L.; Dovidio, JF.; Horwitz, S. Legitimizing the gap: The effects of perceived inequality on its justification. Paper presented at EASP/SPSSI Small Group Meeting, The Great Recession and Social Class Divides; September 4-6, 2014; Princeton University; 2014.

Sanchez, DT.; Garcia, JA. Putting race in context: Socioeconomic status predicts racial fluidity. In: Fiske, ST.; Markus, HR., editors. Facing social class: How societal rank influences interaction. New York: Russell Sage Foundation; 2012. p. 216-233.

Shafir, E., editor. Behavioral foundations of policy. Princeton: Princeton University Press; 2013.

Shafir, E. The psychology of scarcity and inequality. Paper presented at EASP/SPSSI Small Group Meeting, The Great Recession and Social Class Divides; September 4-6, 2014; Princeton University; 2014. 
Sherif M. Crisis in social psychology: Some remarks towards breaking through the crisis. Personality and Social Psychology Bulletin. 1977; 3(3):368-382.

Spears, R.; Suhlmann, M. The permeability paradox: Individual mobility poses problems for group loyalty. Paper presented at EASP/SPSSI Small Group Meeting, The Great Recession and Social Class Divides; September 4-6, 2014; Princeton University; 2014.

Stamkou, E. How norm violators shape social hierarchies: Only low-ranking individuals grant power to rule breakers. Paper presented at EASP/SPSSI Small Group Meeting, The Great Recession and Social Class Divides; September 4-6, 2014; Princeton University; 2014.

Stangor C, Lynch L, Duan C, Glas B. Categorization of individuals on the basis of multiple social features. Journal of Personality and Social Psychology. 1992; 62(2):207-218.

Steele, CM. Whistling Vivaldi: How Stereotypes Affect Us and What We Can Do. New York: Norton; 2010.

Stephens, NM.; Fryberg, SA.; Markus, HR. It's your choice: How the middle-class model of independence disadvantages working-class Americans. In: Fiske, ST.; Markus, HR., editors. Facing social class: How societal rank influences interaction. New York: Russell Sage Foundation; 2012. p. 87-106.

Stephens, NM. Let's talk about class: Closing the achievement gap for first-generation college students. Paper presented at EASP/SPSSI Small Group Meeting, The Great Recession and Social Class Divides; September 4-6, 2014; Princeton University; 2014.

Swencionis, JK.; Fiske, ST. More human: Individuation in the 21 st century. In: Bain, P.; Vaes, J.; Leyens, J-Ph, editors. Humanness and dehumanization. New York: Psychology Press, Taylor \& Francis; 2014. p. 276-293.

Swencionis, JK.; Fiske, ST. Self-promote up, ingratiate down: status comparisons drive warmthcompetence tradeoffs in impression management. Paper presented at EASP/SPSSI Small Group Meeting, The Great Recession and Social Class Divides; September 4-6, 2014; Princeton University; 2014.

Tablante, CB.; Fiske, ST.; Moya, M. Lower-class heroes: Influence of target social class on perceptions of deservingness. Paper presented at EASP/SPSSI Small Group Meeting, The Great Recession and Social Class Divides; September 4-6, 2014; Princeton University; 2014.

Tajfel, H.; Turner, JC. The social identity theory of intergroup behavior. In: Austin, WG.; Worchel, S., editors. The social psychology of intergroup relations. Chicago: Nelson-Hall; 1979. p. 7-24.

Taylor SE. Health psychology: The science and the field. American Psychologist. 1990; 45(1):40-50. [PubMed: 2404437]

Travaglia LK, Overall NC, Sibley CG. Benevolent and hostile sexism and preferences for romantic partners. Personality and Individual Differences. 2009; 47(6):599-604.

Turner, JC.; Hogg, MA.; Oakes, PJ.; Reicher, SD.; Wetherell, MS. Rediscovering the social group: A self-categorization theory. Cambridge, MA: Basil Blackwell; 1987.

Urada D, Stenstrom DM, Miller N. Crossed categorization beyond the two-group model. Journal of Personality and Social Psychology. 2007; 92(4):649-664. [PubMed: 17469950]

Van Lange, PAM.; Kruglanski, AW.; Higgins, ET., editors. Handbook of theories of social psychology. Thousand Oaks, CA: Sage; 2012.

Vasiljevic M, Crisp RJ. Tolerance by surprise: Evidence for a generalized reduction in prejudice and increased egalitarianism through novel category combination. PLoS ONE. 2013; 8(3):e57106. [PubMed: 23483895]

Velasquez-Manoffaug M. Lions and Tigers and Bears, Oh, MY! Should you fear the pizzly bear? New York Times Magazine, p. MM32. 2014 Aug 17. Online: August 14, 2014, http:// www.nytimes.com/2014/08/17/magazine/should-you-fear-the-pizzly-bear.html?_r=0.

Vertovec S. Super-diversity and its implications. Ethnic and racial studies. 2007; 30(6):1024-1054.

Wilson, TD. Redirect: Changing the Stories We Live By. New York: Little Brown; 2011. 